\title{
Leibniz's Mill Arguments Against Materialism
}

Stewart Duncan

\section{INTRODUCTION}

Of all Leibniz's arguments against materialism, probably the best known is the mill argument. In section 17 of the "Monadology", Leibniz argues that thought - which he calls perception cannot be explained by "shapes and motions", using the example of an allegedly thinking machine that has been enlarged so one can walk into it, as one can walk into a mill. In the enlarged machine, says Leibniz, "we will never find anything to explain a perception". ${ }^{1}$ From this he seems to conclude that there could be no mechanical or material explanation of thought. Just how Leibniz's argument works is not clear. It has been thought variously to proceed from inexplicability, ${ }^{2}$ from the subjective unity of representation, ${ }^{3}$ and from Leibniz's definition of perception as the expression of a multitude in a simple. ${ }^{4}$ And it has been questioned whether there is really an argument there at all. ${ }^{5}$

"Monadology" 17 is brief and cryptic, and it is hard to see how to resolve these debates over interpretation, but there are other relevant texts. There is a version of the mill argument in the New Essays, and another version in a 1702 letter to Bayle. I focus on those texts in this paper. Both contain arguments against a material, mechanical understanding of the mind, and make prominent use of the example of a mill. They also come from a period, 1702-4, in which Leibniz had several encounters with materialism. The New Essays themselves were one, given Locke's

\footnotetext{
${ }^{1}$ I use several abbreviations in referring to editions and translations of Leibniz: AG for R. Ariew and D. Garber (ed.), Philosophical Essays (Indianapolis: Hackett, 1989); G for to Gerhardt's edition of Leibniz's Philosophische Schriften (Berlin: Weidmannsche Buchhandlung, 1875-90); L for L. Loemker (ed.), Philosophical Papers and Letters (Dordrecht: Kluwer, 1989); NE for P. Remnant and J. Bennett's translation of the New Essays (Cambridge University Press, 1996); and WFNS for R.S. Woolhouse and R. Francks (ed.), Leibniz's 'New System' and Associated Contemporary Texts (Oxford University Press, 1997). In referring to works of Descartes, I use the abbreviation AT to give page references to the edition of Adam and Tannery, and CSM to give references to the translation of Cottingham, Stoothof, and Murdoch in The Philosophical Writings of Descartes (Cambridge University Press, 1984). I use the abbreviation Essay for Locke's Essay concerning Human Understanding, using the edition of P.H. Nidditch (Oxford University Press, 1975). ${ }^{2}$ J. Searle, Intentionality (Cambridge University Press, 1983), p. 268.

${ }^{3}$ M.D. Wilson, Ideas and Mechanism (Princeton University Press, 1999), pp. 388-406.

${ }^{4}$ P. Lodge and M. Bobro, "Stepping back inside Leibniz's Mill”, Monist 81 (1998), pp. 554-73.

${ }^{5}$ A. Savile, Leibniz and the Monadology (London: Routledge, 2000), p. 105.
} 
thought that materialism might be true. Damaris Masham had proposed to Leibniz an argument against an unextended mind, which Leibniz had himself attributed to Hobbes as an argument for materialism. ${ }^{6}$ Leibniz had engaged repeatedly with John Toland, who was arguing for a materialist explanation of the mind. ${ }^{7}$ Materialism was very much on Leibniz's mind at this point. The mill arguments of these years are worth examination as part of this engagement with materialism, never mind any further implications they have.

The rest of this paper examines Leibniz's mill arguments, beginning with and focusing on the earlier texts. Section 2 looks at a 1702 letter to Pierre Bayle, where Leibniz gives a mill argument that derives the falsity of materialism from his definition of perception. Section 3 looks at a different mill argument in the Preface to Leibniz's New Essays, which is based on considerations of inexplicability. Section 4 then considers the relationship between those two arguments. Section 5 turns to the argument of "Monadology" 17, arguing that it is the same sort of argument seen in the New Essays. Section 6 then discusses other interpretations of Leibniz's arguments, particularly the idea that Leibniz was deducing the simplicity of the thinking substance from the unity of representation.

\footnotetext{
${ }^{6}$ On Leibniz's engagement with Masham as it relates to materialism, see S. Duncan, "Leibniz on Hobbes's Materialism”, Studies in History and Philosophy of Science 41 (2010), pp. 11-8. In Masham's letters to Leibniz, see her claim of "not being able to conceive the existence of that which is nowhere" (WFNS 209, G 3.350) and her explanation that "my own belief that there is no substance whatever unextended is ... grounded upon this that I have no conception of such a thing" (WFNS 216-7, G 3.359). For Leibniz's attribution of similar thoughts to Hobbes, see section 7 of “On Nature Itself” (AG 213-4, G 4.508).

${ }^{7}$ Three letters survive of Leibniz's 1702 discussion with Toland: Leibniz's first letter (G 6.499508, L 547-553, AG 186-92), Toland's reply (G 6.508-14), and Leibniz's response (G 6.514-9). In 1704 Toland published his Letters to Serena (London). Leibniz's comments on that book are published in G. Tognon, "Leibniz et Toland: Una lettre inédite à propos de Letters to Serena", in Leibniz: Werk und Wirkung. IV. Internationaler Leibniz-Kongress (Hannover: G.W. Leibniz-

Gesellschaft, 1983), pp. 784-93. For further discussion, see S. Brown, "Two Papers by John Toland: His 'Remarques Critiques sur le Systême de M. Leibnitz...' and the last of his Letters to Serena”, Rivista I Castelli di Yale, 4 (1999), pp. 55-79; S. Brown, "The Leibniz-Toland Debates on Materialism and the Soul at the Court of the Queen of Prussia", in H. Poser (ed.), Nibil Sine Ratione: Mensch, Natur, und Technik im Wirken von G. W. Leibniz, VII. Internationaler Leibniz-Kongress (Berlin: G.W. Leibniz Gesellschaft, 2002), vol. 1, pp. 147-54; S. Duncan, "Toland, Leibniz, and Active Matter", Oxford Studies in Early Modern Philosophy, forthcoming; and F.H. Heinemann, "Toland and Leibniz", Philosophical Review 54 (1945), pp. 437-57.
} 


\section{LEIBNIZ'S 1702 LETTER TO BAYLE AND THE PERCEPTION DEFINTION ARGUMENT}

I begin with the first of the earlier texts. This is a 1702 letter from Leibniz to Pierre Bayle. It was part of a debate that also involved the materialist Toland. Leibniz and Bayle, who had first corresponded in the 1680s, had been engaged in debate following the publication of Leibniz's "New System" in $1695 .{ }^{8}$ Leibniz and Toland, meanwhile, argued about materialism and related issues in the early years of the eighteenth century. These two discussions became intertwined after Bayle argued against materialist explanations of thought in his Historical and Critical Dictionary. Toland wrote to Bayle, arguing that Bayle's arguments were ineffective. Bayle responded to Toland in a note in the second edition of the Dictionary. ${ }^{9}$ Leibniz, meanwhile, heard of Toland's letter and addressed it in one of his own letters to Bayle, using that as another occasion to argue against Toland's materialism.

In note C to the Dictionary article "Dichaearchus", Bayle argued against materialist explanations of the mind..$^{10}$ The main argument of that note seems to run as follows.

1. If feeling belongs to body, then either (a) it does so essentially, or (b) it does so as a modification.

2. But not (a), because then all bodies would have feeling.

3. And not (b), because a modification lost is replaced by another of the same kind (a colour by a colour, a degree of motion by another degree of motion), but when a body loses feeling it is not replaced like this. So

4. Feeling does not belong to body.

Bayle's arguments against Toland are deeply rooted in Cartesian views about ontology. ${ }^{11}$ The Cartesian roots of Bayle's views are again evident in his response to Toland in note L, which hinges on claims about the essence of extended substance, and this having nothing to do with sensation and thought. The embedding of Bayle's arguments in Cartesian metaphysical

\footnotetext{
${ }^{8}$ For descriptions of the Bayle-Leibniz exchange, see M.R. Antognazza, Leibniz (Cambridge University Press, 2009), pp. 420-1; G 3.23-8; and WFNS 68-71.

${ }^{9}$ Toland's letter to Bayle is apparently no longer extant. Elisabeth Labrousse, in discussing this exchange, refers only to Leibniz's letter to Bayle, and also confirms the thought that it is Toland's letter to which Bayle is responding in note L to "Dichaearchus". See Pierre Bayle (Paris: Alin Michel, 1996), p236n.

${ }^{10}$ P. Bayle, Historical and Critical Dictionary: Selections, translated by Richard Popkin (Indianapolis: Hackett, 1991), pp. 64-7.

${ }^{11}$ See T. Ryan, Pierre Bayle's Cartesian Metaphysics (New York: Routledge, 2009), p. 40.
} 
structures meant that he did not have an argument that was likely to convince a materialist, for it was highly unlikely that they would accept his premises.

The relevant passage in Leibniz's letter to Bayle begins with a description of Toland's view, then provides a series of considerations against it, including the mill example and an argument involving the example of mirror images. ${ }^{12}$ Then there are further arguments about compounds and simples, and claims about perception in simple substances. This all seems to be aimed at the discussion of Toland's view.

In 1702 Leibniz thought that Toland was a materialist. Indeed, he thought that Toland was a sort of Hobbesian, a materialist believer in a plenum rather than an atomist. " ${ }^{13}$ "Our learned Englishman", says Leibniz, "seems also to claim that matter can become able to think, as it can become round, and thus that a certain organization, or a certain shape, can produce thought, and that when that organization is destroyed, thought will cease" (WFNS 129, G 3.68). The view is that thought is produced by matter, in particular by the mechanical features of matter. This view, says Leibniz, is mistaken, and he reports that he has told Toland so and why. The discussion, here and elsewhere, is largely conducted in terms of whether thought works mechanically, rather than whether it works materially. For the sort of materialists Leibniz had in mind, such as Hobbes and Toland (at least as Toland's view was in 1702) this was a distinction without a difference, for they thought that matter worked mechanically.

Leibniz's explanation then turns to the example of the mill.

Even if we had eyes as penetrating as you like, so as to see the smallest parts of the structure of bodies, I do not see that we would thereby be any further forward. We would find the origin of perception there as little as we would find it in a watch, where the constituent parts of the machine are all visible, or in a mill, where one can even walk around among the wheels. For the difference between a mill and a more refined machine is only a matter of greater and less.

\footnotetext{
${ }^{12}$ Leibniz's letter to Bayle exists in three versions. Here I consider the longest version, one "without place and date", for it contains by far the longest discussion of the mill and related examples. There is a second version, marked "not sent". And there is a third, still shorter, version, dated "Berlin, 5 December 1702". Thus the version I discuss may be a long first draft of something that Leibniz edited down considerably, not what he actually sent to Bayle. On these versions see WFNS 71 and G 3.69n.

${ }^{13}$ Several readers have thought of Toland as a sort of Spinozist. For recent discussions of that question, see T. Dagron, Toland et Leibniz: L'invention du néo-spinozisme (Paris: Vrin, 2009); S. Duncan, forthcoming; and J. Israel, Enlightenment Contested (Oxford University Press, 2006), p. 184.
} 
We can understand that a machine could produce the most wonderful things in the world, but never that it might perceive them (WFNS 129, G 3.68).

Here the example of the mill is one of three, accompanied by the example of the watch and the example of our having "eyes as penetrating as you like". In each of the three cases we see bodies and their mechanical interactions, but in none of these cases do we see anything that is the sort of thing that could explain perception. The example of the penetrating eyes makes the point that it is not a peculiar fact about middle-sized bodies that nothing in them could explain perception. In smaller bodies too, there is nothing to give the necessary explanation. This reflects the view, widely held at the time, that the interactions of small bodies are explicable in the same way (by the same rules of mechanical interaction) as the interactions of larger bodies.

None of the above obviously amounts to an argument for the conclusion that a machine cannot perceive. Leibniz presents a series of examples intended to illustrate and emphasize his point, that Toland is wrong to think that the arrangement and interaction of bodies could possibly explain perception. (That is perception in Leibniz's sense, which is more like what we would usually call thought than what we would usually call perception.) Leibniz does talk about what we can and cannot understand in a way that perhaps suggests an inexplicability argument for the view that machines cannot think (i.e., the argument that we cannot explain how machines can think, so they cannot think). But he does not explicitly make the move from inexplicability to non-existence. There is simply little to go on in the above passage, perhaps even less than in "Monadology" 17.

Leibniz has more to say in the subsequent discussion involving images in mirrors. Among visible things there is nothing which gets nearer to thought than does an image in a mirror (and brain traces could be no more accurate than that is), but the accuracy of that image doesn't produce any perception in the thing it is in. We do not even come close to it, whatever mechanical theory we make up; we remain infinitely far away from it, as must happen with things that are absolutely heterogeneous, just as a surface, when folded up on itself as often as you like, can never become a body (WFNS 129, G 3.68-9).

This text presents an argument about representation and perception. Images in mirrors can be very accurate representations of the things they are images of, but nothing about the accuracy of that representation produces perception. There might be aspects of the body, say traces in the brain, which function themselves as good representations, perhaps representations as good as 
those provided in mirrors. However, Leibniz argues, the fact that one thing has a structure that represents a second thing does not show us that the first thing perceives the second one. A mirror cannot perceive. And as the closest thing to perception there could be in a brain is the kind of representation found in a mirror image, there cannot be perception in a brain either.

Thus we seem to be given the following argument.

1. The closest thing to perception that there might be in a brain is the kind of representation there is in a mirror image. But

2. That kind of representation is not sufficient for perception. So

3. There is no perception in brains.

One obvious question that arises is, why is such a representation not enough for perception? To see this, we need to think about Leibniz's theories of representation and perception. Throughout his philosophical career Leibniz talked about two relations: perception and expression (which is sometimes called representation). Roughly speaking, perception is expression of complexes in or by simples, and expression itself is isomorphism.

Expression requires, Leibniz says in the New Essays, an "orderly relationship" (NE 131). There are similar passages elsewhere in his work. For example, Leibniz said to Arnauld in 1687 that "One thing expresses another, in my usage, when there is a constant and regular relation between what can be said about one and about the other" (L 339, G 2.112). Indeed, several texts suggest that what is crucial for the presence of expression is the presence of isomorphic structures. Thus Alison Simmons, among others, says that representation just is isomorphism: "representation involves an isomorphism between res repraesentans and res repraesentata. Resemblance is the paradigm case, but other forms of isomorphism will do; planar projective drawings represent solids, maps represent cities, musical notation represents a musical composition and so on". 14

Expression is the relation holding between the mirror images, and possibly the brain traces, and the things they express. It is plausible and common to take that relation to be isomorphism. I cannot decisively show that here. But even if expression is not best understood as being isomorphism, it is not the case that the crucial difference between perception and mere expression is that perception involves isomorphism whereas expression does not. Either they

${ }^{14}$ A. Simmons, "Changing the Cartesian Mind: Leibniz on Sensation, Representation and Consciousness", Philosophical Review 110 (2001), pp. 31-75, at pp. 41-2. See also B. Mates, The Philosophy of Leibniz.(Oxford University Press, 1986), p.38, and compare the alternative proposal of M.A. Kulstad, “Leibniz’s Conception of Expression”, Studia Leibnitiana 9 (1977), pp. 55-76. 
both do or neither does. Taking expression to be isomorphism, aside from being a plausible reading, should cause no major problems in the following arguments, where what is crucial is the difference between expression and perception.

What then is perception? For there to be perception, Leibniz repeatedly says, there must be expression, and one other condition must be met. Perception is expression of a multitude by or in a simple (in particular, a simple substance). ${ }^{15}$ As with the definition of perception, we can see the same theme expressed in texts from an extended period in Leibniz's career. Indeed Leibniz gave a definition of perception in the letter to Bayle I have been discussing: "perception is the expression of a multitude in a unity" (WFNS 129-30, G 3.69). ${ }^{16}$

Those views about perception and expression suggest a revised reading of Leibniz's arguments about mirror images and brain traces.

1. Perception is expression by a simple.

2. A mill or brain or a mirror can express something else, but is not simple. So

3. Perception cannot be done by mills or brains or mirrors.

That is, in a brain you might have one of the things needed for perception, a representation, but you will always lack the other. So brains cannot perceive, and the mechanical materialism proposed by Toland must be false.

This argument would be unpersuasive to Toland, in something like the way Bayle's argument would have been. Bayle argued from Cartesian views that materialists were highly unlikely to accept. Leibniz's first premise here is deeply embedded in the Leibnizian system, and not at all likely to be accepted by materialist opponents such as Toland. It is hard to see how Leibniz himself could possibly have thought this line of reasoning would persuade Toland, or anyone else with similar views. Indeed it is so unlikely to persuade Toland that it is plausible to think it was never intended as an argument that might do so. Still, there is something to be said for this line of thought, for it might be a reasonable explanation of Leibniz's reasons for thinking Toland to be wrong. From Leibniz's perspective, Toland cannot be right about perception, because perception is expression by simples, and the thing that Toland thinks perceives is not a

\footnotetext{
${ }^{15}$ For discussion of complexities related to this definition, see M.A. Kulstad, "Some Difficulties in Leibniz's Definition of Perception", in Michael Hooker (ed.), Leibniz: Critical and Interpretive Essays (University of Minnesota Press, 1982), pp. 65-78.

${ }^{16}$ Earlier, Leibniz more than once gave such a definition of perception when writing to Arnauld in 1687 (e.g., L 339, G 2.112). We find similar definitional texts as late as 1715 (L 636, 644; G $6.598,6.608)$.
} 
simple. Saying that would not persuade Toland. But if you start out agreeing with Leibniz about perception, it is a perfectly good explanation of where Toland errs.

\section{THE NEW ESSAYS}

\section{III.i ANOTHER MILL ARGUMENT}

In discussing Locke's Essay, Leibniz considers three possible accounts of the human mind: a materialism on which thought is the natural result of the nature and structure of certain material things (natural materialism); a materialism that requires a miracle for matter to think (miraculous materialism) which is Leibniz's understanding of the view that Locke describes as thought being superadded to matter; and the view that the thinking thing is not material. ${ }^{17}$ The example of the mill shows up in these discussions, and is again used in an argument against materialism about the mind. Leibniz here uses an inexplicability version of the mill argument. He uses the same example of the mill, and reaches the same conclusion, that material systems cannot think, but does so by considering what we can and cannot conceive an explanation of. Consider the following passage, which argues against natural materialism.

As for thought, it is certain, as our author more than once acknowledges, that it cannot be an intelligible modification of matter and be comprehensible and explicable in terms of it. That is, a sentient or thinking being is not a mechanical thing like a watch or a mill: one cannot conceive of sizes and shapes and motions combining mechanically to produce something which thinks, and senses too, in a mass where [formerly] there was nothing of the kind - something which would likewise be extinguished by the machine's going out of order. So sense and thought are not something which is natural to matter, and there are only two ways in which they could occur in it: through God's combining it with a substance to which thought is natural, or through his putting thought into it by a miracle (NE 66-7).

\footnotetext{
${ }^{17}$ Leibniz himself did think at this stage that every mind was always associated with a body. On his arguments for that view, see Duncan, "Leibniz on Hobbes's Materialism”, pp. 15-8. Brown, "The Leibniz-Toland Debates" argues that Leibniz's increasingly clear opposition to the existence of separated souls was a result of his exchanges with Toland.
} 
Here Leibniz is trying to persuade Locke that natural materialism is false, using an intuition about inexplicability: "One cannot conceive ... So...". ${ }^{18}$ We just cannot conceive of thought arising naturally from mechanical interactions, so matter does not think unless God adds thought to it miraculously. A sort of inexplicability is taken to imply a sort of impossibility.

Leibniz distinguishes between "what is natural and explicable and what is miraculous and inexplicable" (NE 66). The application to the case of the possible material mind is apparently straightforward: Leibniz is arguing that a material mind would be inexplicable, and thus miraculous - thought could not arise naturally from a material structure, which we see because we see that thought could not arise explicably from a material structure. Leibniz does grant that "we must not deny what we cannot understand", but nevertheless asserts that "we are entitled to deny (within the natural order at least) what is absolutely unintelligible and inexplicable" (NE 65), and that "everything which is in accord with the natural order can be conceived or understood by some creature" (NE 65). This is based on a view about God: God would not create a world with completely brute and inexplicable connections in it. Leibniz had used this same view about God earlier, in arguing against Locke's view that there are arbitrary, though regular, connections between sensations and the motions that are associated with them $(\mathrm{NE}$ 56). ${ }^{19}$

Leibniz describes non-miraculous modifications of substances as "intelligible". It is important to note that this language conveys both metaphysical and epistemological points. There is a metaphysical aspect: talk about features arising explicably and intelligibly is in part talk about the relation between the apparent feature and the underlying nature. The "modifications" of a subject "must arise from limitations and variations of a real genus, i.e. of a constant and absolute inherent nature” (NE 65). There is also an epistemological aspect to Leibniz's comments. The language of intelligibility and explicability involves references to things doing the understanding and the explaining. Moreover, we should remember Leibniz's acknowledgment that "we must not deny what we cannot understand". In saying that, he is rejecting one inference based on what we can and cannot understand (the one that involves saying that everything I cannot myself now understand the possibility of is impossible) but not all of them. Indeed, we

\footnotetext{
${ }^{18}$ R.M. Adams, Leibniz: Determinist, Theist, Idealist (Oxford University Press, 1994), p. 367, seems to think Leibniz is just granting for the sake of argument (what Adams thinks is) Locke's own view that matter cannot naturally think. I think he is doing more than that, by providing an extra reason with this argument from inexplicability.

${ }^{19}$ On Leibniz's view about sensations here, see Simmons, pp. 37-8.
} 
need some such inference in order to know that thought could not arise from the "limitations and variations" of the corporeal.

If we are to be able to argue as Leibniz does, we will need to have a way of knowing when something is an intelligible modification, and when it is not. Leibniz emphasizes the idea that things in nature must have qualities that "arise from their nature as explicable modifications" (NE 66). He gives examples where he thinks there is this sort of explicability, as when a corporeal thing's shape is explained as a "limitation" of its nature as a corporeal, extended, thing. But that we have the ability to pick out some cases of explicability does not show that we have the ability to pick out cases of "what is absolutely unintelligible and inexplicable". Talking about what arises explicably from a nature seems not to solve the problem, because the fact that we cannot see how some modification arises from a nature might just point to a current lack of insight or (Locke might suggest) a cognitive limitation.

Locke's views about cognitive limitations suggest a question about what Leibniz was trying to do. Why would Leibniz think that this mill argument, or anything like it, would persuade Locke? Could Locke possibly countenance the move from inexplicability to impossibility? One might well think that this is just not Lockean. Consider the discussion in Essay 4.3.6 of some people who are "over-zealous for or against the immateriality of the soul". Locke thinks one would be over-hasty to conclude from the inconceivability of material minds that materialism is false. ${ }^{20}$ Given such statements, what could Leibniz have been thinking in suggesting this argument to Locke?

There is some evidence that suggests Locke himself accepted the impossibility of natural materialism, so Leibniz might have been trying to give him a further reason to accept something he was already inclined to. Essay 4.10 is relevant here, as when Locke says that "it is as impossible to conceive, that ever bare incogitative matter should produce a thinking intelligent being, as that nothing should of itself produce matter" (Essay 4.10.10). ${ }^{21}$ And Leibniz seems to have expected that Locke would agree with him about the inexplicability claim: "I believe you agree, sir, that it is not within the power of a bare machine to give rise to perception, sensation, reason" (NE 379). Still, a certain tension does remain between Locke's doubts about inferences from our lack of understanding, and Leibniz's apparent hope that Locke would accept an

\footnotetext{
${ }^{20}$ See also Essay 2.23.5.

${ }^{21}$ This reading of 4.10 is not unproblematic, in part because it seems to clash with other things Locke says: claims about the equal mysteries of mind and body in 2.23, and the rejection in 4.3.6 of the argument against materialism that material minds are inconceivable.
} 
argument from inexplicability. This tension is to some extent, however, a function of puzzles about how to fit together Locke's various claims about how essences relate to other qualities, about cognitive limitations, and about the possibility of matter thinking. ${ }^{22}$

Whatever exactly Locke thought about the possibility of natural materialism, he was clearly holding open the possibility of superaddition (miraculous materialism), saying that it is "impossible for us, by the contemplation of our own ideas, without revelation, to discover, whether omnipotency has not given to some systems of matter fitly disposed, a power to perceive and think, or else joined and fixed to matter so disposed a thinking immaterial substance" (Essay 4.3.6). Thus Leibniz saw the need to argue against the possibility of miraculous materialism. He did so by arguing that to think that God "gives things accidents which are not 'ways of being' or modifications arising from substances, is to have recourse to miracles and to what the Scholastics used to call 'obediential power"' (NE 379). That is, superaddition would require one to explain the natural world using miracles, which one ought not to do. Leibniz more famously objects to using miracles to explain the natural world in the context of arguing against occasionalism, but was happy to make the point against Locke too. ${ }^{23}$

Given Leibniz's division of the space of possible answers into three - natural materialism, miraculous materialism, and non-materialism - he thought Locke should accept the third. The second is rejected by an argument against the use of miracles in explanation. The first is rejected by the mill argument. Leibniz aimed to persuade Locke against natural materialism or perhaps just reinforce his occasional inclination against natural materialism - with an inexplicability argument. Thus Leibniz was attempting to persuade Locke of the falsity of materialism, not by starting from his definition of perception, but with an argument from inexplicability to impossibility. The mill example is used in the New Essays in an inexplicability argument.

\footnotetext{
${ }^{22}$ The literature on such issues is vast. See among many others M.R. Ayers, "Mechanism, Superaddition, and the Proof of God's Existence in Locke's Essay", Philosophical Review 90 (1981), pp. 210-51; M.D. Wilson, Ideas and Mechanism, pp. 196-214; L. Downing, "The Status of Mechanism in Locke's Essay", Philosophical Review 107 (1998), pp. 381-414; and M. Stuart, "Locke on Superaddition and Mechanism", British Journal for the History of Philosophy (1998) 6, pp. 351379.

${ }^{23}$ Such objections to occasionalism are widespread in Leibniz's work. One example is the argument in the "New System" that Malebranche's system involves "properly speaking, having recourse to a miracle" (AG 143, G 4.483).
} 


\section{III.ii A PARALLEL ARGUMENT}

The mill argument was not the only such argument that Leibniz gave in Preface to the New Essays. Leibniz also addressed a further issue that was puzzling for Locke - how to understand Newton's views about gravity, given a preference for mechanical forms of explanation in the physical world.

So within the order of nature (miracles apart) it is not at God's arbitrary discretion to attach this or that quality haphazardly to substances. He will never give them any which are not natural to them, that is, which cannot arise from their nature as explicable modifications. So we may take it that matter will not naturally possess the attractive power referred to above, and that it will not of itself move in a curved path, because it is impossible to conceive how this could happen - that is, to explain it mechanically - whereas what is natural must be such as could become distinctly conceivable by anyone admitted into the secrets of things (NE 66).

This argument, which is apparently parallel to the later argument about the mill and the material mind, seems to run follows.

1. There is no conceivable mechanical explanation of how matter could possess the Newtonian gravitational power.

2. If there is no conceivable mechanical explanation of how matter could possess a certain power, then (miracles aside) matter could not possess that power. So

3. Matter does not possess the Newtonian gravitational power (miracles aside). Of course gravity, like the mind, should not be explained by miracles. So we might extend this argument, to reach Leibniz's ultimate conclusion. From 3 Leibniz can move to

4. Either matter possesses the Newtonian gravitational power miraculously, or it does not possess it at all. But

5. We should not explain the workings of the physical world using miracles. So

6. Matter does not possess the Newtonian gravitational power.

These further moves are parallel to Leibniz's ruling out explanations of the mind that invoke God's superadding thought to matter.

Leibniz's willingness to use this sort of argument in the case of gravity, as well as the case of the mind, is telling. This really is a form of argument to which he was (at least at some times) committed. Of course, the use of this sort of argument about gravity also draws attention 
to problems with it. Though Newtonian physics is not the ultimate truth about the world, there is a good sense in which Newton was right and Leibniz wrong about the issue here. So Leibniz's argument somehow led him to a false conclusion about the world, in the case of gravity. ${ }^{24}$

The problem with Leibniz's argument about gravity appears to lie in its restriction of the natural powers of matter to those that can be mechanically explained. No doubt Newtonian gravity is in some way conceivable, but a mechanical explanation of it cannot be conceived - it cannot be understood as working by the small objects of the world pushing and pulling on one another like clockwork. Indeed, this aspect of it is just what Locke was struggling with, because of his general attachment to some sort of mechanical picture of the physical world. ${ }^{25}$

The most obvious difficulty with the gravity argument thus appears to arise from the sort of explanation being sought. There is no reason not to think Leibniz was using the same view when giving his argument about the material mind in the next paragraph. There too, Leibniz would have been looking for a material explanation that was within the mechanical framework. Leibniz denied there could be such an explanation of thought, just as he denied there could be one of gravity. Leibniz was offering the same argument about the mind that had just led him, a few lines before, to the wrong conclusion about gravity. Now, it is not clear that allowing nonmechanical physical interactions will make any difference to the conceivability of a material explanation of the mind. So the problem with the gravity argument need not indicate a parallel problem with the mind argument. But it does indicate the difficulty of making reliable judgments of inexplicability, even if one does allow the general sort of argument Leibniz proposes.

\section{III.iii. INEXPLICABILITY ARGUMENTS AND LEIBNIZ'S CRITICISMS OF DESCARTES}

I have argued that Leibniz tried to persuade Locke using an inexplicability argument. However, Lodge and Bobro object to attributing such an argument to Leibniz (pp. 555-8). They use as a text Leibniz's objection, in his 1692 piece on Descartes's Principles, to Descartes's argument for mind-body distinctness (L 383-412, G 4.354-92). ${ }^{26}$

\footnotetext{
${ }^{24}$ For more on Leibniz's views about gravity, see D. Bertoloni Meli, Equivalence and Priority: Newton versus Leibniz.(Oxford: Clarendon, 1993), especially pp. 156-61, and E. Vailati, Leibniz and Clarke (Oxford University Press, 1997), pp. 182-92.

${ }^{25}$ On Locke's discussions of Newtonian gravity, see L. Downing, "Locke's Newtonianism and Lockean Newtonianism", Perspectives on Science 5 (1997), pp. 285-310.

${ }^{26}$ See also Wilson, pp. 390-2.
} 
Descartes argues as follows in section 8 of Part I of the Principles of Philosophy.

In this way we discover the distinction between soul and body, or between a thinking thing and a corporeal thing.

This is the best way to discover the nature of the mind and the distinction between the mind and the body. For if we, who are supposing that everything which is distinct from us is false, examine what we are, we see very clearly that neither extension nor shape nor local motion, nor anything of this kind which is attributable to a body, belongs to our nature, but that thought alone belongs to it. So our knowledge of our thought is prior to, and more certain than, our knowledge of any corporeal thing; for we have already perceived it, although we are still in doubt about other things (CSM 1.195, AT VIIIA.7).

Leibniz describes this argument as "so flimsy a sophism", apparently because of the move from the epistemic to the ontological. All you will be able to conclude here, Leibniz says, is that we can doubt that the soul is corporeal, not that it is not corporeal (L 385, G 4.357-8). There is a certain similarity between the argument Leibniz criticizes here and the one I have attributed to him in the New Essays. Given that similarity, should I worry about the attribution?

Leibniz was opposed to some such arguments (roughly speaking, arguments from conceivability to possibility) but he was not opposed to all of them. ${ }^{27}$ Indeed, in the discussion of Descartes, Leibniz acknowledged that the equivalent argument in the Meditations might not be vulnerable to the same objections as the argument in the Principles. In discussing the argument from the Principles, Leibniz's objection was that the approach of regarding doubtful claims as false, which he regarded as at best a fiction, has been misused. ${ }^{28}$ So Leibniz thought that Descartes's mistake was to argue here from 'x can be doubted' to 'x is false'. But Leibniz himself did not need to accept that move, even in the argument he gave to Locke. The argument Leibniz offered to Locke might be criticized, but it did not rely on the principle Leibniz was criticizing Descartes for using.

There is another reason why it might not be so bad to attribute an argument from inexplicability to Leibniz, at least in the period in which he was thinking about Locke and writing the New Essays. Interesting here is the way in which Leibniz responded to one particular

\footnotetext{
${ }^{27}$ See again Leibniz's comments in the Preface to the New Essays about what we are and are not entitled to deny (NE 65).

${ }^{28}$ See also the comments on Principles I.2 at L 384, G 4.355-6.
} 
argument for materialism. That argument (which Leibniz thought was Hobbes's) moved from the premise that immaterial minds were inconceivable by us, and thought thus inexplicable by us in terms of an immaterial mind, to the conclusion that there are no immaterial minds. Leibniz clearly thought this argument mistaken: mistaken about the human mind, and tending towards atheism as well. However, his objections to the argument were objections to the claims about conceivability, and the imagistic theory of ideas that grounded them. He did not object to the move from inconceivability and inexplicability to nonexistence. ${ }^{29}$ This suggests that Leibniz himself might have had some sympathy with such a move, properly understood, and that whatever we may think about such arguments, Leibniz himself thought them at least possibly reputable.

In sum, though Leibniz did criticize some moves from inconceivability and inexplicability to impossibility, he was not opposed to them all, so there is no general reason to refrain from attributing such arguments to him.

\section{THE RELATIONSHIP BETWEEN LEIBNIZ'S TWO ARGUMENTS}

We find two mill arguments in Leibniz's texts at this time. In the New Essays we find an attempt to persuade of the falsity of materialism about the mind, based on what is (and what is not) explicable. In the 1702 letter to Bayle we find a different argument, based on Leibniz's definition of perception. The first is questionable because of the inexplicability to impossibility move, the second because those to be persuaded will reject the key premise.

There are serious pressures towards each of these two readings, in addition to the narrowly textual ones. The perception definition argument has the virtue of explaining why Leibniz though it was impossible for something like a mill or a brain to think. Even if the claim that perception requires a simple substance has itself no explanation, it can serve as an explanation of the impossibility. Meanwhile the inexplicability argument is something that Leibniz might plausibly have thought would persuade someone. Neither Locke nor Toland was about to accept an argument that began from the claim that perception can only be done by a simple substance.

Moreover, there is some suggestion of the inexplicability argument in the 1702 letter, as well as in the New Essays. This argument is suggested by Leibniz's claim in the letter that "We

\footnotetext{
${ }^{29}$ See Duncan, "Leibniz on Hobbes's Materialism”, pp. 13-5, the texts referred to in note 6 above, and the discussion in the New Essays of Essay 4.3.6.
} 
can understand that a machine could produce the most wonderful things in the world, but never that it might perceive them" (WFNS 129, G 3.68). That is only a suggestion. But the argument's presence in the New Essays gives us some extra reason to think it really is in the 1702 letter as well. Still, whether or not it is correct to find both arguments in that letter, Leibniz did endorse both arguments in roughly the same period. They use the same example, and reach the same conclusion, but in different ways. How do they relate to one another?

The key to this is that the inexplicability claim does not have to occupy the same place in the structure of the argument Leibniz hopes will persuade others as it occupies in the structure of Leibniz's own view. Leibniz claims that thought is inexplicable by shapes and motions. For Leibniz himself, this is ultimately explained by the nature of perception, in particular its being done by simples. But he thinks the inexplicability claim will persuade others for different reasons.

Thus for Leibniz himself, the claims relate to one another as follows.

1. Perception is expression by simples. So

2. It is impossible for a machine to perceive. So

3. We could not explain perception just by reference to a machine.

4. And we should not explain perception by a machine plus a miracle. So

5. We ought to reject mechanical materialism about the mind.

That series of claims, related in that way, is not about to persuade a materialist such as Toland, because it depends so much on the Leibnizian premise 1. Nor could Leibniz have seriously hoped that it would do so. However, a related series of claims might perhaps persuade Toland or Locke. The argument that might do that persuading starts from

3. We could not explain thought just by reference to a machine.

In its persuasive role, that is not given a further explanation. The hope, I take it, is that someone will reflect on examples such as that of the mill and just agree that they do not see anything of the right sort to explain perception. From that, one might move to

2. It is not naturally possible for a machine to perceive. Thus (with some acknowledgment of 4) we come to

5. We ought to reject materialism about the mind.

While in Leibniz's system the structure of reasoning is from 1 to 2 to 3 to 5 , the argument by which he hopes to persuade materialists moves from 3 to 2 to 5 . In each case the claim about inexplicability is important, but it plays different roles. Note how this satisfies the 
pressures leading to both of the readings above. We see why Leibniz himself might have believed the impossibility and inexplicability claims. And we see why he might have thought his argument - at least, one of his arguments - would have persuaded a materialist. The key is to see that the two answers are not the same.

Moreover, this reading makes sense of the structure of the 1702 text, with its suggestion of both arguments. We first get an inexplicability argument involving the mill and other examples, which seems to be supposed to persuade us against materialism, but which provides no explanation of the alleged inexplicability. We then get Leibniz's own explanation of the inexplicability. That itself will not persuade a materialist. But by that point in the text, we are perhaps supposed to have been already convinced of the errors of materialism.

Where does the famous example of the mill fit into this story? It plays a role in motivating premise 3, for those who do not derive it from Leibnizian theory. Thinking about big, and obviously unthinking, machines is supposed to help us see that small machines could not think either, even if we do not grasp exactly why they could not think. The prompted intuition that a machine could not think is not however all of Leibniz's story. He has, within his view, resources to explain the truth of the intuition. But those resources are not, in the first instance, what are supposed to persuade those who disagree with him.

Leibniz is trying to do two things, to explain and to persuade. Sometimes one tries to do the two things at once, with the same argument. But in this case, what is said in explanation and what is said in persuasion are not quite the same thing. There would be something lacking in thinking that either of the two arguments was the whole story. Inexplicability readings invite the question of why the inexplicability exists, for which the definition of perception provides an answer. And perception definition readings invite the question of why anyone should be persuaded, for which the inexplicability considerations provide an answer.

\section{LOOKING AGAIN AT "MONADOLOGY” 17}

I turn now to the "Monadology", and thus to the most famous mill argument text. Notice that two arguments attributed in the literature to "Monadology" 17 occur in earlier mill argument passages. The argument from the definition of perception that appears in the 1702 letter to Bayle

resembles the argument attributed to Leibniz by Lodge and Bobro, and the mill argument of the New Essays resembles the argument attributed to Leibniz by Searle. This suggests that one of those two might be the argument of "Monadology" 17. 
It is helpful to put section 17 in its immediate context, as well as the context of other mill argument passages. Consider the argument of "Monadology" 16.

We ourselves experience a multitude in a simple substance when we find that the least thought we ourselves apperceive involves variety in its object. Thus, all those who recognize that the soul is a simple substance should recognize this multitude in the monad; and Mr. Bayle should not find any difficulty in this as he has done in his Dictionary article, "Rorarius" (AG 215, G 6.609).

Leibniz seems to be arguing as follows.

1. We see from our experience that perception always involves variety, multiplicity, in its object. So

2. Anyone who recognizes that the soul is a simple substance should conclude that perception is the representation of a multitude in a simple. So

3. Bayle should not have objected to Leibniz's understanding perception as he did. That is an argument, or at least half an argument, for Leibniz's definition of perception as the representation of a multitude by a simple. It is, however, an argument that will only convince someone like Bayle who already believes the soul is simple. Toland and other materialists will be unconvinced. What Leibniz needs, in order to convince them, is an argument that the soul is simple.

Thus we come to "Monadology" 17.

Moreover, we must confess that the perception, and what depends on it, is inexplicable in terms of mechanical reasons, that is, through shapes and motions. If we imagine that there is a machine whose structure makes it think, sense, and have perceptions, we could conceive it enlarged, keeping the same proportions, so that we could enter into it, as one enters into a mill. Assuming that, when inspecting its interior, we will only find parts that push one another, and we will never find anything to explain a perception. And so, we should seek perception in the simple substance and not in the composite or in the machine.

Furthermore, this is all one can find in the simple substance - that is, perceptions and their changes. It is also in this alone that all the internal actions of simple substances can consist (AG 215, G 6.609).

This is, I suggest, the missing second half of the argument for the perception definition. 16 aims to show us that perception involves the perception of a multitude, and then 17 aims to show us 
that the multitude must be represented in a simple. The argument for 17 is to work by ruling out the only live alternative: a mechanical understanding of the mind.

That tells us what 17 needs to do. But how does the argument of 17 work? The 'And so' in the middle still involves a gap, or at least an implied premise. But if the aim of 16 and 17 together is to argue for the definition of perception, then that gap cannot be filled by an argument from the definition of perception. Since the other mill argument Leibniz used in the past was an inconceivability argument, it is plausible that this too is one. That is, the mill argument of the "Monadology" is a sort of inconceivability argument. Indeed one might well suspect that it is the same argument that we saw in the New Essays.

My argument here turns on the thought that Leibniz is arguing for the definition of perception in "Monadology" 16-7. Further support for that is provided by looking at the stretch of the "Monadology" from sections 14 to 17 . Section 14 does state the definition, but what follows in 14 is about the perception/apperception distinction, and 15 is about apperception. 16 and 17 then return to the definition, to give reasons for it. If this is indeed the structure, then 17 cannot be deducing anything from the definition of perception, but does make good sense as an inexplicability argument.

\section{OTHER INTERPRETATIONS, OTHER ARGUMENTS}

I have argued that Leibniz gave two mill arguments in the early eighteenth century: one based on his definition of perception, and the other based on the inconceivability of a mechanical explanation of the mind. These correspond to two prominent suggestions about how to interpret the mill argument of the "Monadology". Lodge and Bobro understand "Monadology" 17 as involving an argument from Leibniz's definition of perception. I have argued that this is not the best way to understand "Monadology" 17, though Leibniz did give that argument elsewhere. Searle understands "Monadology" 17 to involve an argument from inexplicability. I have argued that this is the right sort of way to understand the argument of "Monadology" 17, as well as the related argument in the New Essays. This also amounts to a response to the suspicion of Savile that there may be no argument in "Monadology" 17 at all.

There is another prominent reading of the mill argument in the secondary literature. Margaret Wilson argues that Leibniz was, in section 17 of the "Monadology", motivated by considerations of the unity of representation. In arguing for this reading, Wilson connects Leibniz's argument in "Monadology" 17 to one discussed by Kant in the Second Paralogism of 
the Critique of Pure Reason. This is the argument that "representations that are divided among different beings [...] never constitute a whole thought", so "the thought can never inhere in a composite as such. Thus it is possible only in one substance, which is not an aggregate of many, and hence it is absolutely simple". ${ }^{30}$ Leibniz was, on this account, arguing from the subjective unity of representation or consciousness to the objective unity and simplicity of the thinking thing. ${ }^{31}$

That reading aims to explain Leibniz's apparent argumentative jump in the middle of "Monadology" 17, in much the way that my argument that Leibniz is giving an argument from inexplicability does. However, there is reason to think that Leibniz was not giving this sort of argument, from subjective unity to objective simplicity, in "Monadology" 17. The first difficulty is the text itself, which does not appear to state this argument, or to discuss the subjective unity of representation. Wilson's argument makes significant reference to a passage from a letter Leibniz sent to Arnauld in 1687, almost thirty years beforehand (Wilson, p. 397). And she admits that Leibniz is "extremely inexplicit" in making the suggestion she believes he makes (p. 397). That is, Wilson finds relatively little explicit evidence in favour of her interpretation, certainly as a reading of "Monadology" 17, and even as a reading of other passages in Leibniz's work. Secondly, Lodge and Bobro object that Leibniz's argument is supposed to be about all perception, but the argument suggested by Wilson is about the unity of consciousness, and thus just about conscious perception (pp. 558-61). So there are significant difficulties facing Wilson's view as an interpretation of "Monadology" 17. Rather than focusing narrowly on that text, however, the rest of this section considers this interpretation in the same way earlier sections considered other interpretations, by looking at the earlier mill argument texts. ${ }^{32}$

There appears to be little to say about the New Essays in this connection. The arguments about the mind in the Preface do not make use of notions of simplicity and unity. And Leibniz seems not to use the suggested argument from subjective unity to objective simplicity elsewhere in the text. There are however, two possibly related arguments in the letter to Bayle that was discussed in section 2 above. After the passages discussed previously, Leibniz says the following.

\footnotetext{
${ }^{30}$ I. Kant, Critique of Pure Reason, translated by Paul Guyer and Allen W. Wood (Cambridge University Press, 1998), A 352.

${ }^{31}$ On various philosophers' uses of arguments of this type, see T.M. Lennon and R.J. Stainton (ed.), The Achilles of Rationalist Psychology (Dordrecht: Springer, 2008).

${ }^{32}$ J.-P. Schachter, "Leibniz's 'Achilles"', in Lennon and Stainton, pp. 177-91, finds an argument of the alleged sort in the "Monadology", but in section 2, not section 17.
} 
We can also see that since thought is an action of one thing on itself, it has no place among shapes and motions, which could never provide the basis of a truly internal action. Moreover, there must be simple beings, otherwise there would be no compound beings, or beings by aggregation [...] And if there was no change in simple things, there would be no change in compound things either, for all their reality consists only in that of their simple things. Now, internal changes in simple things are of the same kind as that which we understand to be in thought, and we can say in general that perception is the expression of a multitude in a unity (WFNS 129-30, G 3.69).

Leibniz is here moving towards offering arguments for his own view, rather than arguments specifically against the mechanical, materialist picture offered by Toland. The central argument of this passage appears to run as follows.

1. The existence of compounds implies the existence of simples.

2. Change in compounds is explained by change in simples. ${ }^{33}$ So

3. Perception is done by these simples.

There is a good deal one might say about this argument, which invokes familiar Leibnizian themes about simples and compounds. But for current purposes, I note three things. First, this is not an argument from subjective unity to objective simplicity. Secondly, as with the argument from the definition of perception, accepting this argument requires accepting several other Leibnizian claims, so this argument is unlikely to be persuasive to Leibniz's opponents. Thirdly, there is no sign of this argument in "Monadology" 17. So though this is an interesting argument, its presence in the letter to Bayle gives no support to anything like Wilson's reading of "Monadology" 17.

That is the main argument of the above passage. One might perhaps think there is another argument there, in the first sentence's comments about thought being an internal action. Leibniz argues that shapes and motions could not explain an internal action, so thought could not be explained mechanically. But what is an internal action, how do we know that thought is one, and how do we know that such a thing could not be explained mechanically? ${ }^{34}$ However we

\footnotetext{
${ }^{33}$ This premise rules out changes in compounds being explained by changes in the relations between the simples, without the simples themselves changing.

${ }^{34}$ In a letter to Damaris Masham of May 1704, Leibniz argues that we know by experience that souls work by internal action (WFNS 206, G 3.340).
} 
answer these questions, one thing is clear, that this argument, even if it does stand apart from the previous one, is also not an argument from subjective unity to objective simplicity.

Mentions of internal actions do provide a small connection to "Monadology" 17, for the notion of an internal action recurs there. Leibniz concludes "Monadology" 17 by saying that "this is all one can find in the simple substance - that is, perceptions and their changes. It is also in this alone that all the internal actions of simple substances can consist" (AG 215, G 6.609). That is an argument about what the internal actions of simple substances are: they must be perceptions. But in the letter to Bayle, the argument is about what perceptions are: they are internal actions, and thus not to be explained mechanically. Roughly speaking, Leibniz is arguing in the opposite direction. So though there is some connection between the briefly stated argument of 1702 about internal actions and "Monadology" 17, this argument does not provide a model for understanding that section.

Overall, there appears to be little support for the thought that the mill argument (in "Monadology" 17 or elsewhere) is an argument from subjective unity to objective simplicity. There are problems textually with seeing it as the argument of that section. And there is no strong reason to read the other mill argument passages discussed in that way. Leibniz does indeed use arguments that invoke simplicity. But in these passages it is always the objective simplicity of the substance that he refers to, and he does not attempt to infer this from any subjective unity or simplicity.

\section{CONCLUSION}

The mill argument owes its fame to the text of "Monadology" 17, but Leibniz argued in similar ways - using the same example and reaching the same conclusion - in other places. In a 1702 letter to Bayle he offered a mill argument that derived the falsity of materialism from the truth of Leibniz's own definition of perception. Leibniz in effect deduced the falsity of Toland's view from the truth of his own one. The argument offered was not at all likely to persuade Leibniz's materialist opponents, because of the way the key premise was deeply embedded in Leibniz's system. It did however offer a Leibnizian explanation of why Toland was wrong.

Even in that letter, there is the suggestion of another argument, one that hinges upon a claim of inexplicability. Such an argument is more clearly present in the Preface to the New Essays. There Leibniz argued against the view that thought might arise naturally from certain configurations of matter, by arguing that such connections between material structures and 
thought could never be explained. He offered a similar argument against Newtonian gravity. Both arguments are based on Leibniz's view that God would not create a world with arbitrary, inexplicable connections in it. A similar argument from inexplicability also appears to be driving "Monadology" 17. Leibniz could not there have been arguing from his definition of perception, because he was in the middle of arguing for that definition. Rather he was once more inviting his readers to reflect upon what could possibly be explained, and to draw substantive conclusions from those reflections. ${ }^{35}$

\footnotetext{
${ }^{35}$ Earlier versions of this paper were presented to audiences at the Fifth Biennial Margaret Dauler Wilson Conference at the University of Colorado - Boulder, and at the University of Maryland. I thank both audiences for helpful discussions. Thanks too to Julie Silva for her helpful comments.
} 